\title{
An Application of Mass Loss Rate Model with Fuel Response Effects in Fully-Developed Compartment Fires
}

\author{
YUNYONG P. UTISKUL ${ }^{1}$ and JAMES G. QUINTIERE ${ }^{2}$ \\ ${ }^{1}$ Arup Fire \\ 12777 Jefferson Blvd, Suite 200, Los Angeles, CA 90066 USA \\ ${ }^{2}$ Department of Fire Protection Engineering \\ University of Maryland, College Park, MD 20742 USA
}

\section{ABSTRACT}

Fuel responses to the flame and its surroundings are essential to predict the effect of fire on the structures. This study explores the fuel responses and applies them to the common fuel configurations. The study focuses on the fully-developed fires where all available fuel becomes involved and can potentially yield the severest damage to the structural elements. A single-zone fire model is developed along with a fuel mass loss rate model that accounts for the thermal enhancement, oxygen-limiting feedback, and the fuel configuration. An empirical correlation for mixing of oxygen into the lower floor layer essential for the modeling is developed. An experimental program for single-wall-vent compartment using wood crib and heptane pool is performed to validate the model and explore a full range of phenomena associated with fully-developed fires. The simulation from the model is able to capture these phenomena and shows good agreement with the experiments. Some generalities of the fuel mass loss rate and compartment gas temperature are presented using the experimental results and the model simulations. The developed model is able to give burning time and temperature in a fire for any fuel, scale and ventilation.

KEYWORDS: compartment fires, fuel mass loss rate, burning rate, vitiated oxygen, radiation feedback

\section{NOMENCLATURE LISTING}

$\begin{array}{clcl}A_{F} & \text { fuel area } & T & \text { temperature, gas temperature } \\ A_{F, b} & \text { fuel burning area } & T_{o} & \text { ambient temperature } \\ A_{s} & \text { compartment wall surface area } & T_{l} & \text { temperature of the gas feeding flame } \\ c_{p} & \text { specific heat } & W & \text { width } \\ D & \text { diameter } & Y_{o x} & \text { oxygen fraction in the compartment } \\ H & \text { height } & Y_{o x, o} & \text { oxygen fraction in the free burning } \\ \Delta h_{c} & \text { heat of combustion per unit fuel mass } & Y_{o x, l} & \text { oxygen fraction feeding the flame } \\ L_{f} & \text { mean beam length of flame } & Z & \text { smoke layer height } \\ L & \text { heat of gasification } & \text { Subscripts } \\ \dot{m}_{b} & \text { burning rate } & F & \text { fuel } \\ \dot{m}_{F} & \text { fuel mass loss rate } & f & \text { flame } \\ \dot{m}_{e} & \text { mixing rate } & l & \text { lower layer, feeding the flame } \\ \dot{m}_{o} & \text { incoming air flow rate } & o & \text { opening, ambient, free burning } \\ N & \text { neutral plane height } & v & \text { vaporization } \\ \dot{Q} & \text { energy release rate } & w & \text { wall } \\ \dot{q}^{\prime \prime} & \text { heat flux } & \text { Greek } & \\ r & \text { stoichiometric oxygen to fuel ratio } & \varepsilon & \text { emissivity } \\ S & \text { window sill height } & \kappa & \text { absorption coefficient } \\ S & \text { stoichiometric air to fuel ratio } & \rho & \text { density }\end{array}$

\section{INTRODUCTION}

A fully-developed fire is defined as the stage of fire where all available fuels become involved and the fire burns at its maximum potential according to the limit amount of the available fuel (fuel-controlled fire) or 
the available air supply (ventilation-controlled fire). The fully-developed stage is the greatest concern to the design for the structural stability and the safety of the firefighters. In most buildings, fires in common residential spaces and offices become ventilation-controlled when the fully-developed stage is reached. In ventilation-controlled fires, all of available fuel gases are not consumed by the flames and these gases can burn as they pass through the openings causing the flames to emerge windows and doors. For a large fire at the fully-developed stage, the compartment is often filled with the smoke and the layer interface is close to the floor. Such a condition can be termed the well-mixed stage where the gas is assumed to have uniform properties throughout the compartment. A single-zone model assumption is usually suitable for this type of fires. In a structural fire protection design, the information of the maximum temperature and fire duration is necessary to obtain a proper fire protection system for a given room with ventilation and fuel load configurations. To achieve such a requirement the burning rate and the fuel mass loss rate must be correctly calculated by taking into account for the fuel response to the thermal feedback enhancement from the enclosure and the vitiated oxygen effects. Current design tools including correlations and mathematical fire models do not address the fuel response; hence the burning time and temperature may not be properly predicted. This paper presents a study that may fulfill the incompleteness of the current design tools by establishing a single-zone fire model that addresses the fuel response to the thermal feedback and limited oxygen effect and potentially gives the burning time and temperature for any fuel, scale, and ventilation.

\section{COMPARTMENT BURNING RATE AND FUEL BEHAVIOR}

The burning rate is defined as the rate at which the fuel, usually but not exclusively in the gas-phase, is consumed by the chemical reaction within the enclosure. The burning rate plays a significant role in compartment fire because it represents how much energy is released into the system. The energy release rate or fire power, $\dot{Q}$, within the enclosure is given as

$\dot{Q}=\Delta h_{c} \dot{m}_{b}$.

where $\dot{m}_{b}$ is the burning rate. In some literature, however, the term burning rate was used to describe the fuel mass loss rate. While these two rates may arguably follow the same trend; they have completely different meaning. The fuel mass loss rate refers to the rate at which a condensed-phase fuel is decomposed to gases due to the energy transferred from its surrounding heat sources such as flames, hot gas, and enclosure walls. We can describe the relationship for the mass loss rate and the burning rate as follow:

$\dot{m}_{b}= \begin{cases}\dot{m}_{F} & ; \phi<1 \\ \dot{m}_{o} / s & ; \phi \geq 1\end{cases}$

where $\dot{m}_{o}$ is the incoming air flow rate and the global equivalence ratio $\phi=\dot{m}_{F} / \dot{m}_{o} \cdot s$. In compartment fire experiments the fuel mass loss rate can be directly measured using weighing cells to track the weight of the fuel over time; however, measurement for the burning rate may not be done directly especially in the under-ventilated condition. In order to predict the burning rate, the fuel mass loss rate must be accurately known as appears in Eq. (2. This is always true even for the under-ventilated condition, where burning depends on available air, because the fuel mass loss rate also determines the burning state. The fuel mass loss rate can be given as

$\dot{m}_{F}=\dot{m}_{F, o}^{\prime \prime} A_{F, b} \frac{Y_{o x, l}}{Y_{o x, o}}+\frac{\dot{q}_{E x t e r n a l}}{L}$,

Where $\dot{m}_{F, o}^{\prime \prime}$ is the free burning rate and $\dot{q}_{\text {External }}$ is the total external heat feedback from smoke and compartment wall surfaces. The first term on the right hand side of Eq. 3 represents the vitiated oxygen effect on the flame heat flux [1] and the second term is responsible for the thermal feedback from smoke and compartment wall surfaces.

A common correlation for the free burning rate per unit area of large liquid pool fires ( $D>0.2 \mathrm{~m}$ ) is given

as [2] $\dot{m}_{F, o}^{\prime \prime}=\dot{m}_{F, \max }^{\prime \prime}\left(1-e^{-\kappa_{f} L_{f}}\right)$, where $\dot{m}_{F, \max }^{\prime \prime}$ is the asymptotic value for fuel mass loss rate. For a cylindrical shape flame with a diameter $(D), L_{f}=0.66 D$ [3]. A correlation describing the time-average 
free burning rate per unit exposed area for wood cribs, $A_{F}$, was established by Heskestad [4] as $\dot{m}_{F, o}^{\prime \prime}=0.968 C_{w} b^{-1 / 2}\left(1-\exp \left(-(s b)^{1 / 2} A_{C, o} / 0.02 A_{F}\right)\right)$, where $b$ is the thickness dimension of a stick, $\mathrm{s}$ is the spacing between sticks, $A_{C, o}$ is the cross-sectional area of the vertical crib shafts, and $C_{w}$ is the empirical wood crib coefficient given by Block [5].

The total external radiation feedback can be given as $\dot{q}_{E x t e r n a l}=\dot{q}_{E x t, b}+\dot{q}_{E x t}$, where $\dot{q}_{E x t, b}$ and $\dot{q}_{E x t}$ are the net radiation feedback to the flaming fuel area and non-flaming fuel area respectively and can be given as follows

$\dot{q}_{E x t, b}=F_{g}\left(1-\varepsilon_{f}\right) \varepsilon_{g} A_{F p, b}\left(T^{4}-T_{o}^{4}\right)+F_{w}\left(1-\varepsilon_{f}\right)\left(1-\varepsilon_{g}\right) A_{F p, b}\left(T_{w}^{4}-T_{o}^{4}\right)$,
$\dot{q}_{E x t}=F_{g} \varepsilon_{g}\left(A_{F p}-A_{F p, b}\right)\left(T^{4}-T_{v}^{4}\right)+F_{w}\left(1-\varepsilon_{g}\right)\left(A_{F p}-A_{F p, b}\right)\left(T_{w}^{4}-T_{v}^{4}\right)$

where $F_{g}$ is the shape factor from the fuel to the compartment gas, $F_{w}$ is the shape factor from the fuel to the walls, $A_{F p, b}$ is the projected flaming fuel surface area, and $A_{F p}$ is the total projected fuel surface area.

\section{NEAR VENT MIXING}

To predict the fuel mass loss rate, the oxygen feeding the flame, $Y_{o x, l}$, needs to be estimated. In room fires when the vent is small and the smoke layer descends close to the floor, the entering cold fresh air stream can be contaminated by the smoke due to the buoyancy and shear mixing occurring near the vent. This phenomenon, called vent mixing, leads to the reduction in oxygen feeding the flame and it is therefore an important factor to explain the effect of ventilation on the fuel mass loss rate in the compartment fires. A method of characterizing the near vent mixing behavior has not been well established; however, some investigations have been carried out. McCaffrey and Quintiere [6] suggested that the flow rate of the mixed stream can be significant relative to the vent flow rate. Zukoski et al. [7] developed a correlation for the mixing rate from saltwater simulation experiments. Zukoski’s correlation was based on an assumption that the cold incoming flow through the opening would behave like a point source buoyant plume entraining the hot gas in the upper layer and then descending downward to the lower layer. However, Zukoski pointed out for the point source plume approach that it was illogical for two reasons. First, the plume theory was developed to describe the far field of a weakly buoyant, axisymmetric plume while the doorway plume is not axisymmetric. Secondly, the doorway incoming flow has initial momentum which is not always negligible. In this study, the mixing model was investigated based on Quintiere and McCaffrey [8] that the incoming cold air behaved like a jet entering the doorway with a characteristic velocity and diffusing downward because of buoyancy. While the cold air descended, the surrounding hot gas was entrained with a velocity that is proportional to the incoming flow characteristic velocity. From this concept, we obtain a ratio of mass entrained to the total incoming mass flow rate or mixing ratio as

$$
\frac{\dot{m}_{e}}{\dot{m}_{o}} \sim\left(\frac{T_{o}}{T}\right)\left(1+\frac{N-S}{W_{o}}\right)\left(\frac{N-Z}{N-S}\right) \text {. }
$$

Hence, we wish to obtain a correlation for the mixing ratio empirically in the form of Eq. [5]. Single-vent compartment fire experiments were conducted to establish the correlation for the mixing at the quasi-steady state. The fuel supply rate was controlled and the measurements include the oxygen concentration vertical profiles, gas temperature, smoke layer heights, and neutral plane height. From the steady-state conservation of oxygen, the mixing ratio, $\dot{m}_{e} / \dot{m}_{o}$, can be estimated from the measured oxygen concentration in the lower and upper layer as $\dot{m}_{e} / \dot{m}_{o}=\left(Y_{o x, o}-Y_{o x, l}\right) / Y_{o x, l}-Y_{o x, u}$. From the experiments, it was found that the mixing ratio is well correlated with Eq. [5] and a linear relationship up to an apparent asymptote for the mixing ratio of 1.28 . This can be put into an expression for the mixing ratio as follow

$$
\begin{array}{ll}
\dot{m}_{e} / \dot{m}_{o}=1.14 \cdot \Psi & \text { for } \Psi<1.1 \\
\dot{m}_{e} / \dot{m}_{o}=1.28 & \text { for } \Psi \geq 1.1
\end{array},
$$

where $\Psi$ represents the right hand side of the Eq. 5. A well-mixed condition in the compartment fire is defined when the layer interface or the smoke is close to the floor. The opening geometry and fire size plays an important role on the location of the layer interface. When this condition prevails, the properties 
of the gas in the compartment are said to be uniform and a single zone model can be effectively used to predict the gas temperature and species in the compartment. Nevertheless, in reality a sharp gradient of the oxygen concentration still exists near the floor. In other words, the oxygen that is feeding the flame is not the same as in the bulk smoke layer even though the smoke layer is close to the floor. In order to overcome this, the mixing can be used as a mechanism to help defining the local oxygen feeding the flame in a single zone model. We choose to use a constant maximum value of 1.28 for the mixing ratio as suggested for the well-mixed compartment fires with a single-wall-vent configuration. This limit would apply when the layer is close to the floor. The local gas temperature and oxygen mass fraction feeding the flame can be then be calculated as $Y_{o x, l}=\frac{Y_{o x, o}+\left(\dot{m}_{e} / \dot{m}_{o}\right) Y_{o x, u}}{1+\left(\dot{m}_{e} / \dot{m}_{o}\right)}$ and $T_{l}=\frac{T_{o}+\left(\dot{m}_{e} / \dot{m}_{o}\right) T_{u}}{1+\left(\dot{m}_{e} / \dot{m}_{o}\right)}$ respectively.

\section{ENERGY RELEASE CRITERIA}

A flame extinction condition can be defined by a flammability line that is based on a critical flame temperature below which the extinction occurs and no energy is generated into the system. The flame temperature $T_{f}$ is given as [9]

$c_{p}\left(T_{f}-T_{l}\right)=\frac{\Delta h_{c}-L+c_{p}\left(T_{v}-T_{l}\right)+\frac{\dot{q}_{E x t, b}^{\prime \prime}}{\dot{m}_{b}}}{1+\left(r / Y_{o x, l}\right)}$.

Based upon the extinction flame temperature, the criteria for energy release rate (or burning rate) given in Eq. 1 is expressed as

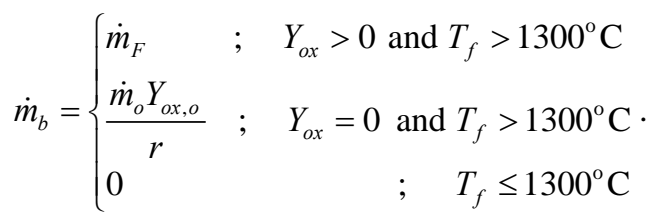

\section{BURNING AREA IN VENTILATION-CONTROLLED FIRES}

Thomas and Bennetts[10] observed flames partially burning over a series of liquid fuel trays in their experimental study on long and wide enclosures. They reported that after ignition the flame formed itself at the front of the fuel tray closest to the vent. Later, when the fuel in the front tray was exhausted, the flame moved towards the rear of the enclosure (away from vent) to the next adjacent tray. This behavior takes place because the compartment reaches the ventilation-controlled condition where the burning is controlled by the amount of supplied air. We also experienced the same phenomena in our experiment programs with distributed fuel packages all over the floor. Motivated by such observations, we offer a reason why only a certain amount of fuel area will react with the limited amount of air supply. The flame therefore burns only on this certain area to match its needed fuel, and then "moves" when the local fuel is exhausted. The following analysis is put forth to estimate the burning area in ventilation-controlled fire. From Eq. 2, the expression for the fuel burning rate can be given as

$\dot{m}_{b}=\dot{m}_{F, o}^{\prime \prime} A_{F, b} \frac{Y_{o x, l}}{Y_{o x, o}}+\frac{\dot{q}_{E x t, b}^{\prime \prime} A_{F, b}}{L}$

Recall Eq 2 for the under ventilated condition and substitute into Eq. 9. If we assume that the fuel burns in a circular shape i.e. $A_{F, b}=\pi D_{b}^{2} / 4$, upon rearranging we have

$$
\frac{\pi D_{b}^{2}}{4}=\frac{\dot{m}_{o}}{s} /\left(\dot{m}_{F, o}^{\prime \prime} \frac{Y_{o x, l}}{Y_{o x, o}}+\frac{\dot{q}_{E x t, b}^{\prime \prime}}{L}\right) .
$$

Substituting the emissivities of the smoke and the flame with $D=D_{b}$ into the $\dot{q}_{E x t, b}^{\prime \prime}$ term, we can iteratively solve for the burning diameter, $D_{b}$, and hence obtain the fuel burning area. 


\section{COMPARTMENT FIRE EXPERIMENT AND MODEL APPLICATION}

A series of experiments using a small-scale compartment was conducted in which the quantity and configuration of the fuel were varied under natural ventilation condition of various doorway and window widths. The compartment was built with $2.54 \mathrm{~cm}$ (1 inch) thick Type-M Kaowool board. The compartment inner size was measured $40 \mathrm{~cm} \times 40 \mathrm{~cm} \times 120 \mathrm{~cm}$ (height $\times$ width $\times$ depth). Two kinds of the single-wallvent, doorway-like and window-like, were used. The vent height and the sill height were designed such that they represented the common doorway and widow height in real buildings. The measurements are comprised of fuel mass loss rate, gas temperatures, oxygen concentrations, heat flux to wall surface, and differential pressure near vent. Figure 1 shows the section view of the compartment and the measurement layout. The fuel configurations selected here were the $\mathrm{crib}$ fire and the pool fire. Two types of wood, Oak and Pine, were selected as the material for the crib fire. The crib configurations were designed to have surface controlled burning. Heptane $\left(\mathrm{C}_{7} \mathrm{H}_{16}\right)$ was used for the pool fire tests. Descriptions for wood crib and pool size are presented in Table 1. A range of opening sizes and the fuel loads were selected to span over the ventilation factor, $A_{o} \sqrt{H_{o}} \rho_{o} \sqrt{g} / A_{F}$, to represent the full range of real fire conditions. Table 2 provides the experimental conditions.

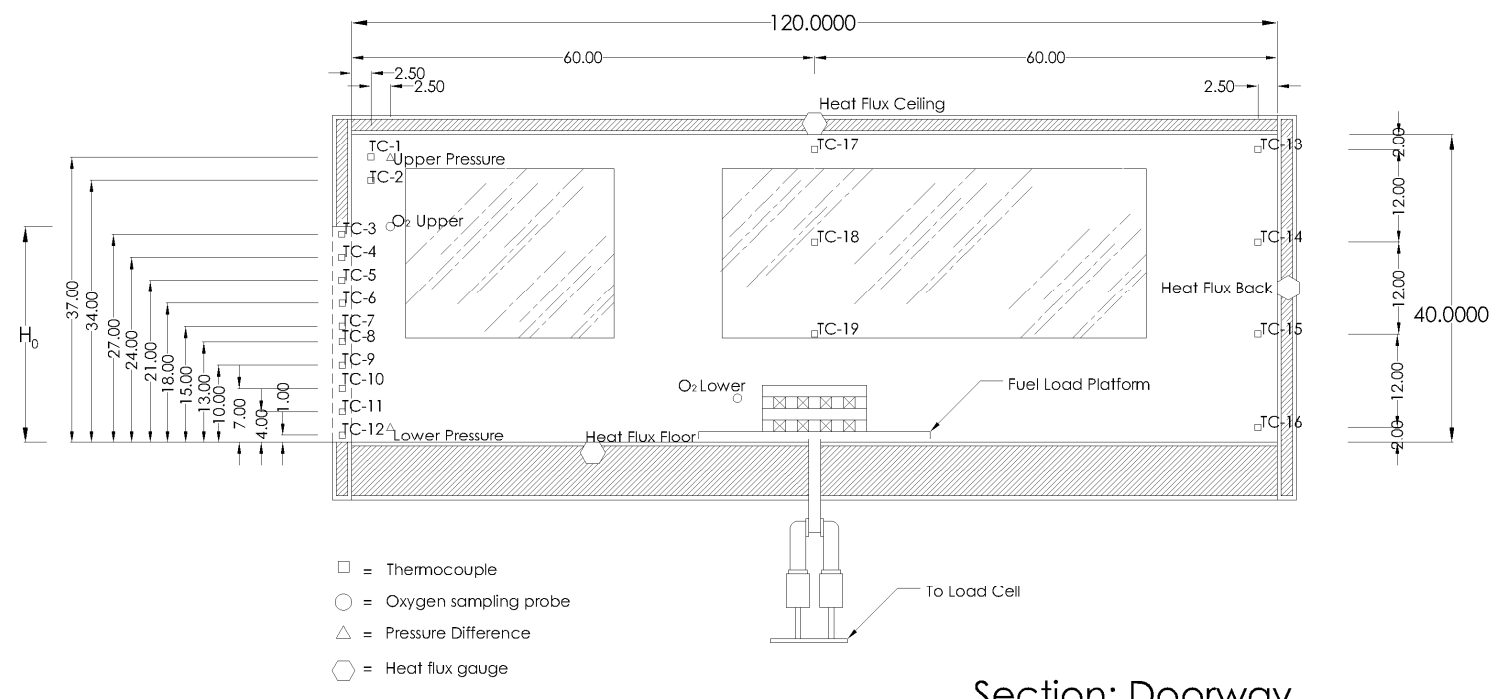

Fig. 1. Schematic of the compartment and measurement layout

From the experiment, the burning can be categorized into 3 cases based on the observed behavior and the global equivalence ratio. The 3 cases (also indicated in Table 2 for each test) are:

Case 1: Steady well-ventilated burning. This is the case where vent is large and the global equivalence ratio is less than one. The flame stabilized above the fuel, and the oxygen in the upper layer is above zero.

Case 2: Steady under-ventilated burning. This case the opening size is reduced and the global equivalence ratio is less than one. The burning is ventilation-limited and the fire area shrinkage occurs. Oxygen in the upper layer is at or near zero. The oscillating flame may take place if the extinction criterion, depending on the local temperature and oxygen, is reached. But the oscillation is only a transient stage for this case and the flame eventually reaches the steady stage where no oscillation occurs and become under-ventilated.

Case 3: Unsteady under-ventilated burning. In this case the opening size is the smallest among all cases. Periodic oscillating flame is observed. The global equivalence ratio is less than one; however, the oxygen in the upper layer is above zero. In this case the extinction criterion is reached and the oscillating flame occurs until the fuel is exhausted. The flame does not consume all the oxygen available. 
Table 1: Wood crib and heptane pool description

\begin{tabular}{|c|c|c|c|c|c|c|c|c|c|c|}
\hline Crib & $\begin{array}{c}\text { stick } \\
\text { thickness } \\
(\mathrm{m})\end{array}$ & $\begin{array}{c}\text { Err } \\
\text { or! } \\
\text { Obj } \\
\text { ects } \\
\text { can } \\
\text { not } \\
\text { be } \\
\text { cre } \\
\text { ate } \\
\text { d } \\
\text { fro } \\
\text { m } \\
\text { edit } \\
\text { ing } \\
\text { fiel } \\
\text { d } \\
\text { cod } \\
\text { es. }\end{array}$ & $\begin{array}{c}\text { Err } \\
\text { or! } \\
\text { Obj } \\
\text { ects } \\
\text { can } \\
\text { not } \\
\text { be } \\
\text { cre } \\
\text { ate } \\
\text { d } \\
\text { fro } \\
\text { m } \\
\text { edit } \\
\text { ing } \\
\text { fiel } \\
\text { d } \\
\text { cod } \\
\text { es. }\end{array}$ & $\begin{array}{l}\text { Crib } \\
\text { lengthEr } \\
\text { ror! } \\
\text { Objects } \\
\text { cannot } \\
\text { be } \\
\text { created } \\
\text { from } \\
\text { editing } \\
\text { field } \\
\text { codes. } \\
\text { (m) }\end{array}$ & $\begin{array}{c}\text { Crib } \\
\text { depthErr } \\
\text { or! } \\
\text { Objects } \\
\text { cannot be } \\
\text { created } \\
\text { from } \\
\text { editing } \\
\text { field } \\
\text { codes. } \\
\text { (m) }\end{array}$ & $\begin{array}{l}\text { No. } \\
\text { of } \\
\text { layer }\end{array}$ & Type & Pool & Diameter (m) & $\begin{array}{c}\text { Heptane } \\
\text { volume (ml) }\end{array}$ \\
\hline 1 & 0.012 & 4 & 7 & 0.3 & 0.15 & 5 & Pine & 1 & $7 \times 0.138,3 \times 0.147$ & 90 (each pan) \\
\hline 2 & 0.01905 & 4 & 4 & 0.15 & 0.15 & 5 & Pine & 2 & 0.245 & 300 \\
\hline 3 & 0.012 & 5 & 5 & 0.15 & 0.15 & 4 & Pine & & & \\
\hline 4 & 0.011 & 9 & 9 & 0.25 & 0.25 & 5 & Oak & & & \\
\hline 5 & 0.022 & 5 & 9 & 0.414 & 0.207 & 3 & Oak & & & \\
\hline
\end{tabular}

Table 2: Experimental conditions

\begin{tabular}{|c|c|c|c|c|c|c|c|c|c|}
\hline Test - Case & $\begin{array}{l}\text { Opening } \\
\text { height } \\
H_{o}(\mathrm{~m})\end{array}$ & $\begin{array}{c}\text { Opening } \\
\text { width } \\
W_{o}(\mathrm{~m})\end{array}$ & $\begin{array}{c}\text { Sill } \\
\text { height } \\
S(\mathrm{~m})\end{array}$ & $\begin{array}{c}\text { Fuel } \\
\text { area } \\
A_{F}\end{array}$ & Test - Case & $\begin{array}{c}\text { Opening } \\
\text { height } \\
H_{o}(\mathrm{~m})\end{array}$ & $\begin{array}{l}\text { Opening } \\
\text { width } \\
W_{o}(\mathrm{~m})\end{array}$ & $\begin{array}{c}\text { Sill } \\
\text { height } \\
S(\mathrm{~m})\end{array}$ & $\begin{array}{c}\text { Fuel } \\
\text { area } \\
A_{F}\end{array}$ \\
\hline Crib1D28x15 -2 & 0.28 & 0.15 & 0.00 & 0.234 & "Crib3D28x30 -1 & 0.28 & 0.30 & 0.00 & 0.119 \\
\hline Crib1W14x20 -2 & 0.14 & 0.20 & 0.14 & 0.234 & Crib3D28x40 -1 & 0.28 & 0.40 & 0.00 & 0.119 \\
\hline Crib1W14x32-2 & 0.14 & 0.32 & 0.14 & 0.234 & Crib3W14x32 -1 & 0.14 & 0.32 & 0.14 & 0.119 \\
\hline Crib2D28x05-3 & 0.28 & 0.05 & 0.00 & 0.185 & Crib4D28x15 -2 & 0.28 & 0.15 & 0.00 & 0.403 \\
\hline Crib2D28x15 -2 & 0.28 & 0.15 & 0.00 & 0.185 & Crib5D28x15 -2 & 0.28 & 0.15 & 0.00 & 0.414 \\
\hline Crib2D28x30 -1 & 0.28 & 0.30 & 0.00 & 0.185 & Pool1D28x15-2 & 0.28 & 0.15 & 0.00 & 0.155 \\
\hline Crib2D28x40 -1 & 0.28 & 0.40 & 0.00 & 0.185 & Pool2D28x15-2 & 0.28 & 0.15 & 0.00 & 0.047 \\
\hline Crib2W14x06 -3 & 0.14 & 0.06 & 0.14 & 0.185 & Pool2D28x30 -2 & 0.28 & 0.30 & 0.00 & 0.047 \\
\hline Crib2W14x32-2 & 0.14 & 0.32 & 0.14 & 0.185 & & & & & \\
\hline
\end{tabular}

Figure 2 shows the measurements and predictions from Case 1 (Crib2D28x30) where gray lines and plots represent the measurements and dark solid lines are for model predictions. The predicted flame effect (the first term on the right-hand-side of Eq 3) and the thermal feedback (the second term on the right-hand-side of Eq 3) are also presented. Gas temperature data shown here were taken at the opening (TC 3 to TC 7).
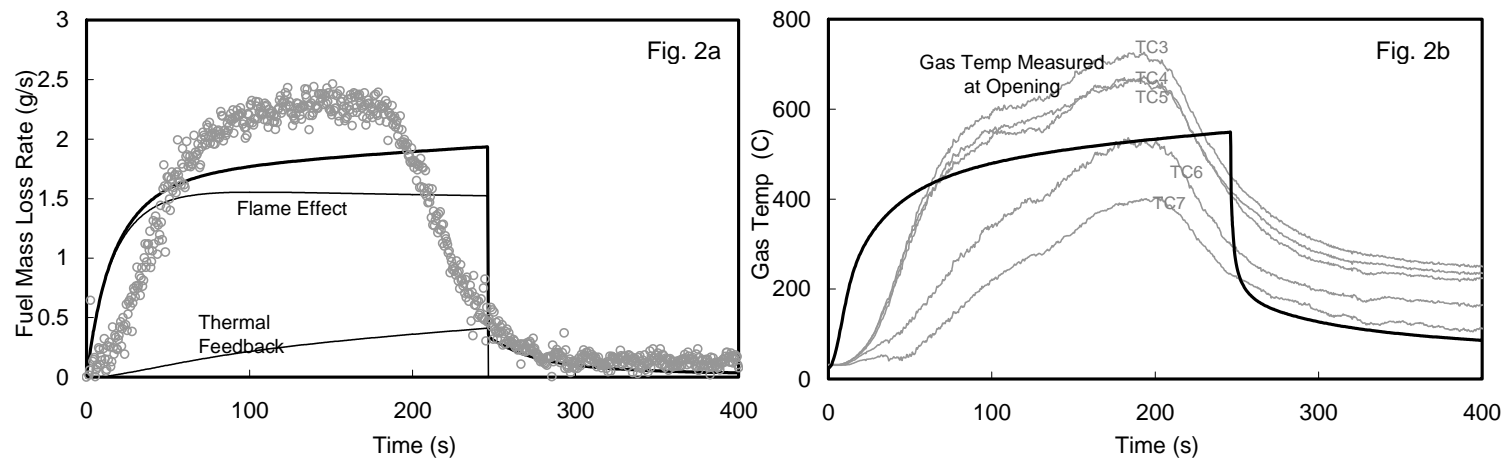

Fig. 2. Experiment and prediction from Crib2D28x30-Case 1, GER $=0.45$ 
Figure 3 shows the results of wood crib (Crib1W14x32) for Case 2. In this test as the fire became ventilation-controlled (oxygen in the upper layer reached zero), the fire area shrinkage occurred. This behavior was observed in both experiment and prediction. An attempt to estimate the shrinking burning area has been made from video observation and also presented along with the prediction from the model. The model matches well with the mass loss rate and the maximum gas temperature measured at the vent. The compartment fuel mass loss rate is lower than its free burning value because of two reasons: 1) the oxygen effect is more dominant than the thermal effect and 2) the reduction in burning area due to ventilation limited condition. Although the reduction in the measured mass loss rate is evident, the measured $\mathrm{O} 2$ feeding the flame only slightly drop from the ambient condition. We believe this is due to uncertainty in $\mathrm{O} 2$ measurement and the probe location. Similar fire area shrinkage behavior is presented in Fig. 4 for heptane pool fire (Pool1W28x15). In this test a series of 10 heptane pans were distributed over the load platform. The ignition was started at the fuel pan located closest to the vent and the flame propagated through all other pans almost immediately. Since the heptane fuel exposing area was large and the gasified fuel was more than a stoichiometric need, the burning condition reached the ventilation-limited condition quickly. This is shown by the measured oxygen approaching near zero percent at about $20 \mathrm{~s}$ after ignition. Shrinking in burning area was observed and the flame was then stabilized near the vent. This case is an example of the classical ventilation-limited burning where the most of the flame burns outside of the vent. Note that the gas temperature measured across the vent in this case is basically the flame temperature. Despite the enhancement from enclosure thermal feedback, the measured fuel mass loss rate is much lower than the free burning rate because of the reduction in the burning area and the change of the flame location. As for the model prediction in this case, the model shows a sharp peak in the fuel mass loss rate about $5 \mathrm{~s}$, then a sharp decrease due to the ensuing ventilation-limited condition. The shrinking in burning area predicted by the model is consistent to the estimation made from the video observations and the reduction in mass loss rate due to area shrinking is well captured. Since the fire area shrinkage is evident in the ventilation-limited fire as shown by our result, this phenomenon can be responsible for the reduction of the fuel mass loss rate in the ventilation-limited condition and can explain why the fuel mass loss rate follows the same trend as the "burning rate" in ventilation-limited fires.
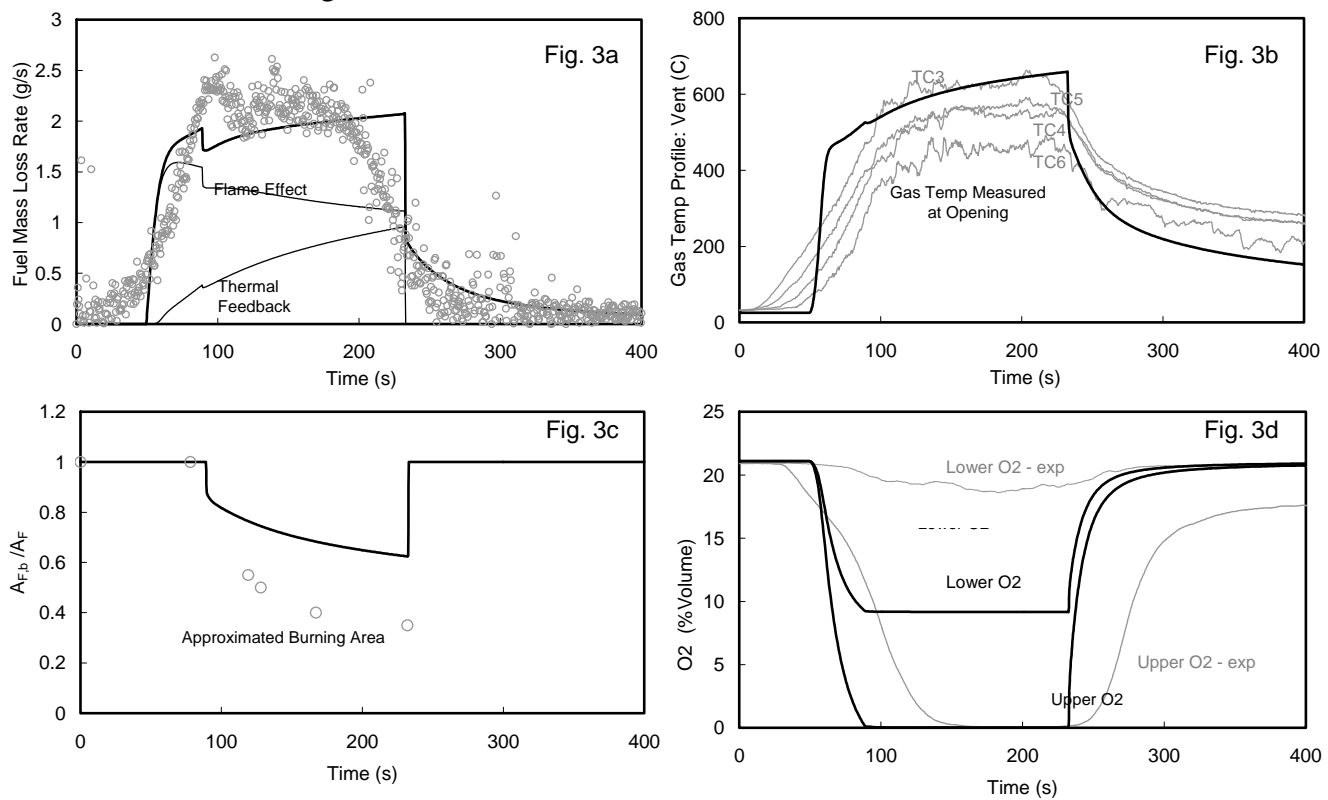

Fig. 3. Experiment and prediction from Crib1W14x32-Case 2, GER $=1.2$

The unsteady flames categorized in Case 3 usually occur in a very low ventilation condition and can appear in several forms such as a periodically oscillating flame stabilizing above the fuel bed, and a ghosting flame that drifts away from the fuel bed with temporally extinction. Takeda and Akita [11] have observed the unstable oscillation flames of methanol and PMMA pool in their compartment fire experiments, and identified the ventilation regime that these behaviors were seen. Chamchine et al. [12] have observed this type of unsteadiness flame in their experiments using a hydrocarbon gas fuel. In this study, the unsteady 
flame of wood crib fires (Crib2D28x5) is presented in Fig. 5. In this test, a slow frequency (approximately $0.3-0.5 \mathrm{~Hz}$ ) was observed for the oscillating flame clearly seen after 1 min and lasted until the fuel was exhausted. The oscillations, or on-off flame phenomena, were evident from the measurements of the pressure difference and the gas temperatures at the vent. We offer an explanation for this flame behavior as follows: As the oxygen concentration feeding the flame decreases the flame becomes weak [1] and is almost extinguished, the compartment temperature also reduces. The sudden change in temperature causes the change in the differential pressure and induces the fresh air into the compartment. This fresh air then revitalizes the flame which later causes the sudden increase in temperature and again consumes most oxygen; hence the process repeats. The model is able to capture the oscillating phenomenon as shown in the predicted mass loss rate and the pressure differences. Nevertheless, it is worth mentioning that although the oscillating flame phenomena involves the extinction and re-ignition events, the current single zone model uses the critical flame extinction criteria, Eq. 7, for both events; a true ignition model has not been included in the current work. In this case, although the global equivalence ratio is more than one, the oxygen in the upper layer from both measurement and prediction shows more than zero percent. This means that all oxygen is not consumed due to the temporary flame extinction. In other words, the flame reaches its extinction criteria before the ventilation limited condition prevails.
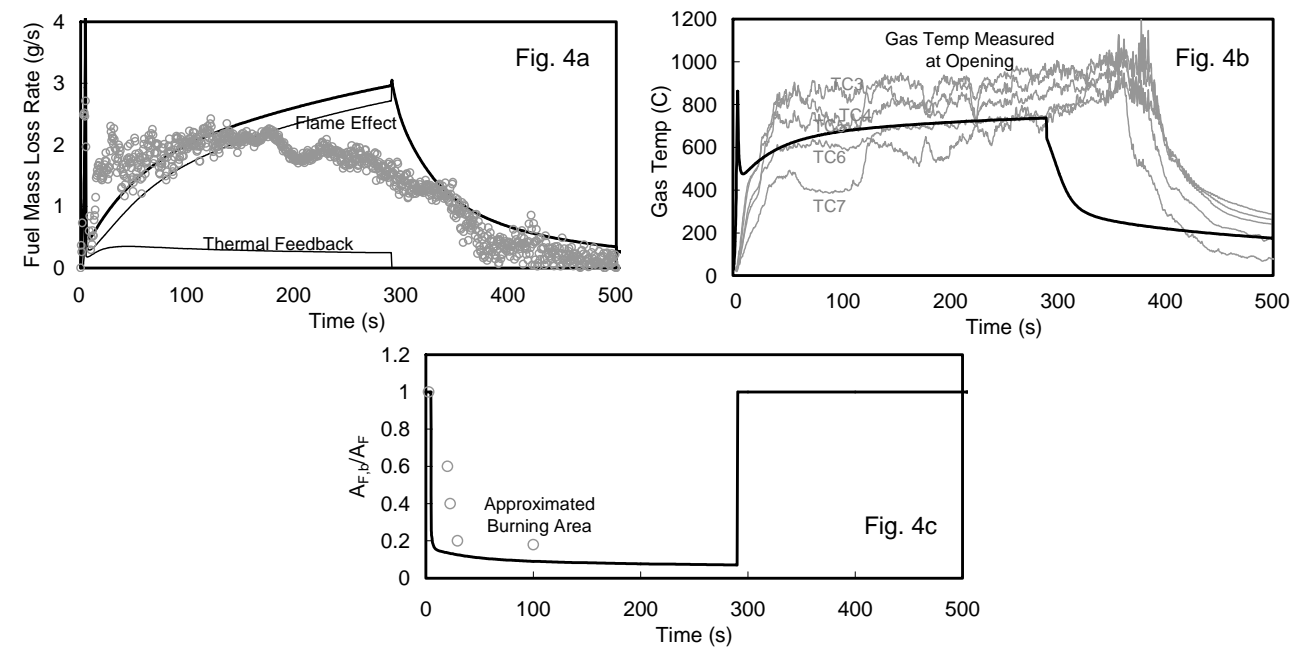

Fig. 4. Experiment and prediction from Pool1W28x15-Case 2, GER = 3
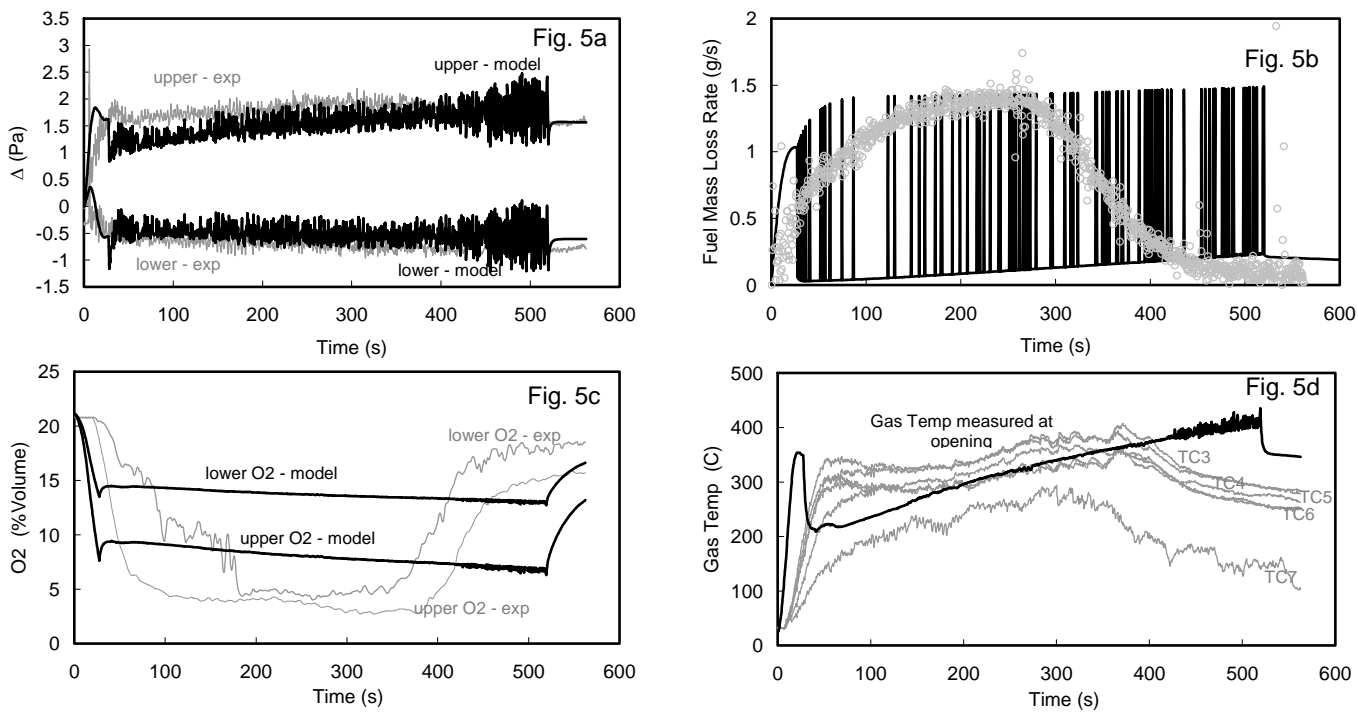

Fig. 5. Experiment and prediction from Crib2D28x5-Case 3, GER = 1.5 
In order to present the experiment results and the model prediction in a global perspective, an average peak value was determined for the fuel mass loss rate and the upper layer gas temperature. The average peak value for both measured and predicted variables was determined in the following manner. The time interval corresponding to the fuel mass changing from 80 to 30 percent of its initial mass was identified. All variables were then numerically averaged over this time interval to yield the average peak values. Figure 6 presents the average peak value of the fuel mass loss rate in terms of the effect of the ventilation ( $A_{o} \sqrt{H_{o}} \rho_{o} \sqrt{g} / A_{F}$ ) and the wall heat loss $\left(A_{s} / A_{F}\right)$. The average peak temperatures are also presented in the same manner in Fig. 8.

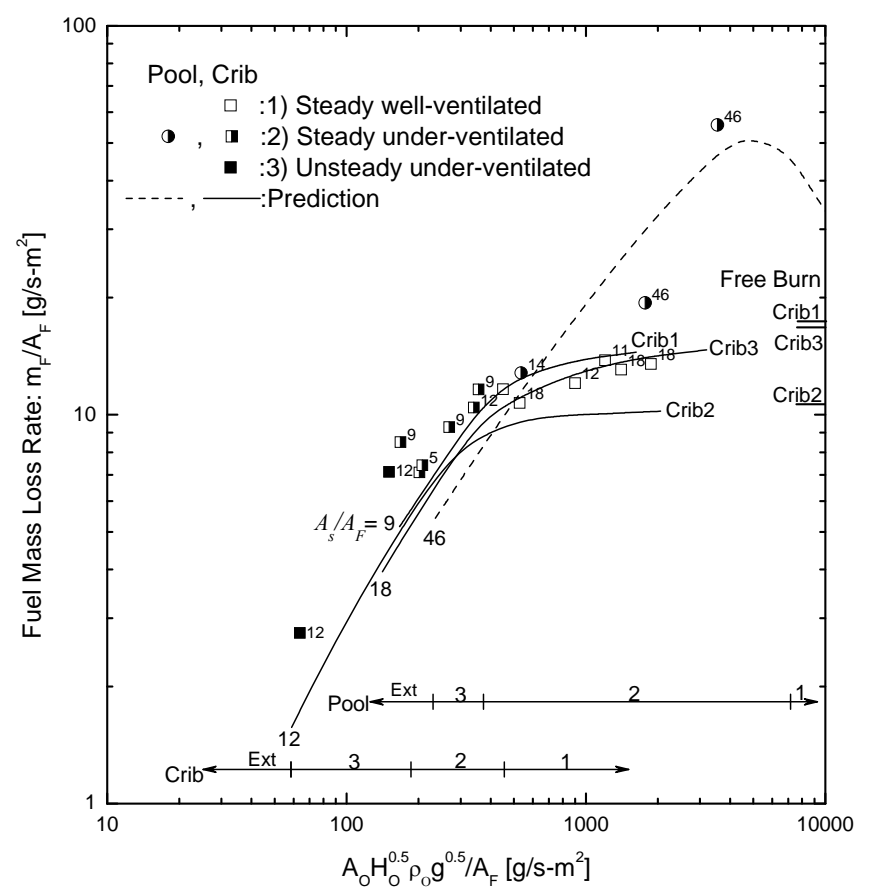

Fig. 6. Dependence of the peak average fuel mass loss rate on ventilation and wall heat loss

The free burning rate is also presented on the right-vertical axis for each crib in Fig 6. The trend predicted by the model generally agrees well with the experiment for both wood crib and heptane fires. The regimes of burning (case 1 to case 3) based on the observation in the simulation are illustrated on the plot using the horizontal arrow-head line. The number marked on each regime corresponds to the case 1 to case 3 and the abbreviation "Ext" designates the complete flame extinction. As shown by the experiments and simulations on the figure, the burning behavior regime of the heptane pool and wood crib fire do not coincide with each other. For instance, at the same ventilation factor $\left(A_{o} \sqrt{H_{o}} \rho_{o} \sqrt{g} / A_{F}\right)$ of $1000 \mathrm{~g} / \mathrm{m}^{2} \mathrm{~s}$, the pool fire is already in its ventilation-limited range while the crib fire is still in the well-ventilation regime. The prediction of the crib shows that in the well-ventilated regime (case 1), the thermal feedback enhancement does not exhibit a strong effect on the mass loss rate and the flame (or oxygen) effect is more dominant as seen by the less value of the crib mass loss rate than its free burning rate. This is also consistent with the experimental result. In addition, no trend is observed for the area ratio, $A_{s} / A_{F}$, in the well-ventilated regime because the thermal effect is small and the crib mainly burns according to its free burning. In other words, for non-porosity-controlled cribs, the stick size is responsible for the mass loss rate of the different crib configuration in the well-ventilated regime. In the under-ventilated regime (case 2 and 3), a general observation from the model and the experiment is that the mass loss rate decreases as the ventilation decreases. However, the wood crib burning dependence on $A_{s} / A_{F}$ becomes clearer from the simulation as the burning is now controlled by the air inflow, oxygen reduction in the lower layer and higher gas temperatures as the amount of fuel $\left(A_{F}\right)$ is increased. Hence, without the scale differences, for ventilationlimited fires, the smaller the ratio $A_{s} / A_{F}$, the higher the mass loss rate. 


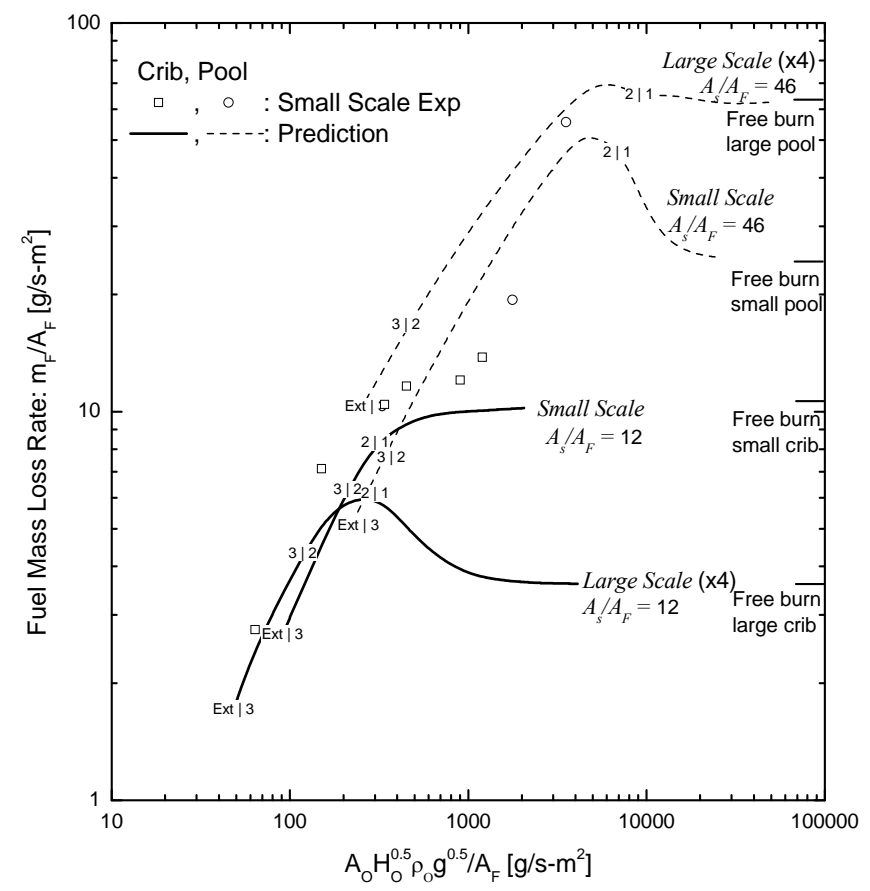

Fig. 7. Scale and fuel type effects on the compartment fuel mass loss rate

The simulation from the single-zone model is used to investigate the effect of the scale on the burning. The compartment used in the large-scale simulation is geometrically scaled up 4 times from the compartment size used in the experiment. This gives a compartment height of $1.6 \mathrm{~m}$. Crib 2 and Pool 1 are also scaled up similarly to preserve the $A_{s} / A_{F}$ ratio. Note that the number of the sticks and layers of the crib does not change; only the stick length and thickness increase by 4 . The mass of the fuel is consistent with the increased volume. The results are presented in Fig. 7. The experimental data from Crib 2 and Pool 1 are also included. On each prediction line, the marked number signifies the boundary of the burning regime. For instance, " $2 \mid 1$ " indicates the boundary between case 1 and case 2 (the steady well-ventilated and the under-ventilated regime). Note that the free burning rate per unit area of the large scale crib is less than the small scale crib because of the larger thickness $(b)$, while the free burning rate per unit area of the large pool fire is larger then the small-scale one. The simulation shows for the small-scale pool that at the near ventilation limited (moving Case 1 to Case 2) the thermal effect is dominating as evident from the increase of the mass loss rate to a higher than its free burning value. In the large-scale pool case the thermal effect is less significant. This is reasonable because the larger-scale heptane pool fire has a higher flame emissivity than the small-scale ( $\varepsilon_{f, p o o l}=0.68$ vs. 0.22 ); hence, the external heat feedback is "blocked" more by the sootier large-scale flame. However, the wood crib fires exhibit an opposite behavior. In the small-scale crib, at the near ventilation limited, the oxygen effect is more dominated while in the large-scale crib the mass loss is enhanced more by the thermal feedback. This could be due to the nature of the heptane pool flame that is much sootier than the wood crib fire. In other words, the emissivities of both large-scale and small-scale wood crib are generally small ( $\varepsilon_{f, \text { wood crib }}=0.18$ vs. 0.05 ); the higher thermal feedback in the large-scale case can penetrate through the wood crib flame and enhance the burning more than the smallscale case. In the ventilation limited regime (Case 2 and Case 3 ) the large-scale configuration shows a higher mass loss rate in both wood crib and the heptane pool fire. Moreover, the flame oscillation in the large-scale simulation seems to take place at a lower ventilation condition than that in the small-scale. The flame extinction regime of the large-scale is also changed to a lower ventilation condition.

Figure 8 shows the peak average gas temperature from experiment and the simulation with the ventilation factor. The peak average values in the experiment are determined for both temperatures measured at the vent and near the back wall. The upper end of the error bar represents the peak average value of the vent temperature and the lower end for the back wall. The plot between each end signifies the space average temperature from these two locations. The trend mapped by the simulation follows the experiment data 
reasonably well. The highest temperature from the simulation for both wood crib and heptane pool fire is found to be at the boundary of well-ventilated and under-ventilated regime, or at the point where the global equivalence ratio is unity. The effect of the wall heat loss to the temperature is quite obvious that the gas temperature increases as the ratio $A_{s} / A_{F}$ decreases.

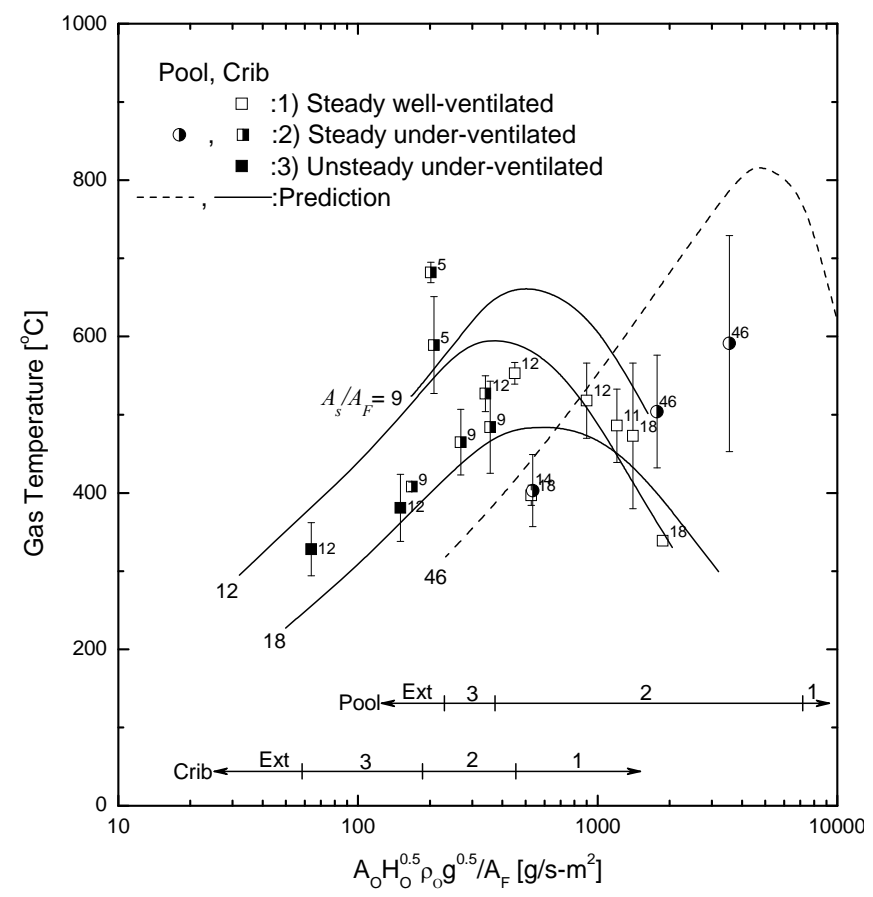

Fig. 8. Dependence of the peak average gas temperature on ventilation and wall heat loss

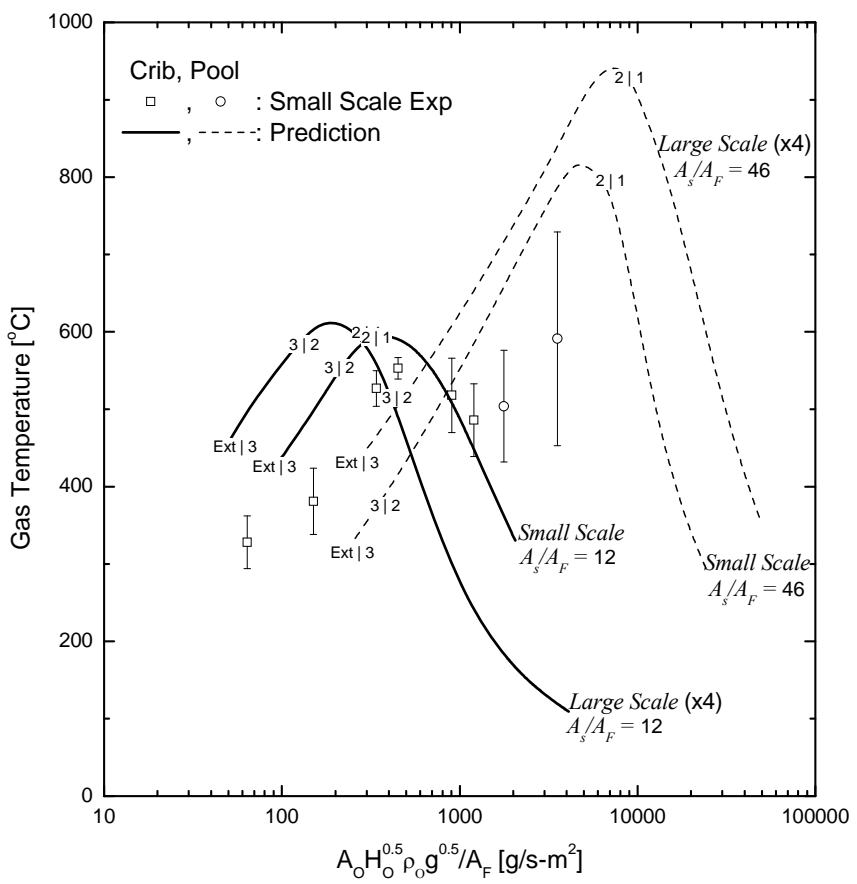

Fig. 9. Scale and fuel type effects on the compartment fuel mass loss rate 
The scale effect on the gas temperature is presented in Fig. 9. For the liquid pool fire, the temperature predicted in the large-scale is higher than the small-scale throughout the range of the ventilation. As for the wood crib the large-scale only shows higher temperature than the small-scale in the ventilation limited regime. The temperature from the large-scale simulation exceeds the small-scale temperature at the boundary of the well-ventilated to under-ventilated regime; this confirms a strong thermal feedback from the hot gas layer to the fuel mass loss rate increasing significantly at this location as described in Fig. 7. Note that the temperature presented here is the average peak temperature, which does not represent the maximum temperature recorded in the experiments and the simulations. The maximum peak temperature measured from the largest wood crib experiment in our study is found to be at $890^{\circ} \mathrm{C}$ and the prediction for this test yield a maximum temperature of $840{ }^{\circ} \mathrm{C}$

\section{CONCLUDING REMARKS}

Applications of the fuel mass loss rate model that takes into account of the fuel response to vitiated oxygen and external radiation heat flux have been presented using a single-zone compartment fire model. The model is capable of predicting the gas temperature and the fuel mass loss rate that can relate to the burn time in a fire for any fuel, scale and ventilation. The model shows good agreement with the experiment and is able to reveal the full range of phenomena associated with fully developed fires as observed in the experiment: response of fuel to thermal and oxygen effects, oscillation, and extinction. Fuel type, scale, ventilation, and heat loss effects have been demonstrated with the model simulations and the experiments. Generally, the higher temperature and mass loss rate are achieved with the bigger scale and the lower ratio of $A_{s} / A_{F}$. The maximum temperature and mass loss rate is achieved when $\phi \approx 1$. The scale effect on the flame emissivity of the heptane pool fires is more than that of the wood crib fires. The fire area shrinkage can be the reason for the fuel mass loss rate to follow the same trend as the burning rate in ventilationlimited fires.

\section{REFERENCES}

[1] Tewarson, A., J.L. Lee, and R.F. Pion. The Influence of Oxygen Concentration on Fuel Parameters for Fire Modeling, Symp Int Combust 18th. 1981, doi:10.1016/S0082-0784(81)80061-6.

[2] Babrauskas, V., Estimating Large Pool Fire Burning Rates. Fire Technology, 1983(19): p. 251, doi:10.1007/BF02380810.

[3] Karlsson, B. and J.G. Quintiere, Enclosure Fire Dynamics. 1999, Florida: CRS Press.

[4] Heskestad, G. Modeling of Enclosure Fires. in Symp Int Combust 14th. 1972, doi: 10.1016/S00820784(73)80092-X.

[5] Block, J.A. A Theoretical and Experimental Study of Nonpropagating Free-Buring Fires. in Symp Int Combust 13th. 1970. Salt Lake City, Utah.

[6] McCaffrey, B.J., and Quintiere, J. G., Buoyancy-Driven Counter-current Flows Generated by a Fire Source. Heat Transfer and Turbulent Buoyant Convection, 1977. 2: p. 457-472.

[7] Zukoski, E.E., Experimental Study of Environment and Heat Transfer in a Room Fire. 1978, California Institute of Technology Pasadena, CA.

[8] Quintiere, J.G., McCaffrey, B.J., The Burning of Wood and Plastic Cribs in an Enclosure: Volume I. 1980, National Bureau of Standards: Washington, DC.

[9] Quintiere, J.G. and A.S. Rangwala, A Theory of Flame Extinction Based on Flame Temperature. Fire and Materials, 2003. 28: p. 387-402, doi:10.1002/fam.835.

[10] Thomas, I.R. and I.D. Bennetts. Fires in Enclosures with Single Ventilation Openings Comparison of Long and Wide Enclosure. in Sixth IAFSS. 1999, doi:10.3801/IAFSS.FSS.6-941.

[11] Takeda, H., Akita, K. Critical Phenomenon in Compartment Fires with Liquid Fuels. in Symp Int Combust 18th. 1981, doi:10.1016/S0082-0784(81)80057-4.

[12] Chamchine, A.V., et al. Interpretation of small and medium scale experiments with an enclosed burner fire. in Interflam2004. 2004. Edinburgh, UK. 